\title{
Engine Technology Challenges for the High-Speed Civil Transport Plane
}

Robert M. Plencner, Ajay Misra, Edwin J. Graber, Jr., Robert J. Shaw, and Gary T. Seng

Lewis Research Center, Cleveland, Ohio

Prepared for the

20th Advanced Measurement and Ground Testing Technology Conference sponsored by the American Institute of Aeronautics and Astronautics Albuquerque, New Mexico, June 15-18, 1998

National Aeronautics and

Space Administration

Lewis Research Center 
Trade names or manufacturers' names are used in this report for identification only. This usage does no: constitute an official endorsement, either expressed or implied, by the National Aeronautics and Space Administration.

Available from

NASA Center for Aerospace Information 7121 Standard Drive Hanover, MD 21076

Price Code: A03
National Technical Information Service 5285 Port Royal Road Springfield, VA 22100 Price Code: A03 


\title{
Engine Technology Challenges for the High-Speed Civil Transport Plane
}

\author{
Robert M. Plenener \\ National Aeronautics and Space Administration \\ Lewis Research Center \\ Cleveland, Ohio 44135 \\ Ajay Misra \\ Edwin J. Graber, Jr. \\ Rober J. Shaw \\ Gary T. Seng \\ National Aeronautics and Space Administration \\ Lewis Research Center \\ Cleveland, Ohio 44135
}

Introduction

Ongoing NASA-funded (ref. 1,2) and privately funded studies continue to indicate that an opportunity exists for a second generation supersonic commercial airliner, or High-Speed Civil Transport (HSCT), to become a key part of the 21 st century international air transportation system. Long distance air travel is projected to be the fastest growing segment of the air transportation market by the turn of the century with increases at about 5 percent per annum over the next two decades (ref. 3-5). This projection suggests that by the year 2015 , more than 600,000 passengers per day will be traveling long distances. predominantly over water. These routes would provide the greatest potential for an HSCT to hecome a significant part of the international air transportation system.

The potential market for an HSCT is currently project to be any where from 500-1500) aircraft over the 2005-2030 time period. Such an aircraft fleet size would represent a considerable share of the potential long-range aircraft market. However, this projected HSCT fleet can become a reality only if technologies are developed which will allow an HSCT design that is (1) environmentally compatible and (2) cconomically viable.

Simply stated, the HSCT will be a technology driven airplane. Without significant advances in airframe and propulsion technologies over the levels currently available, there will be no second generation supersonic airliner!
This paper will briefly describe the propulsion technology challenges which must be met prior to any product launch decision being made by industry and the progress toward meeting these challenges through NASA's High-Speed Research (HSR) Program. a partnership between NASA and Bocing. General Electric and Pratt \& Whitney.

\section{Environmental Challenges}

The two environmental challenges that must be met before an HSCT product launch could be considered are atmospheric ozone depletion and airport noise. Meeting these challenges requires advances in propulsion lechnologies, specifically combustor technology to meet the ozone depletion challenge and low noise propulsion system technology to address the airport noise challenge.

\section{Ozone Depletion}

Potential depletion of the Earth's protective ozone layer is attributed to HSCT engine exhaust products, specifically the nitric oxide $\left(\mathrm{NO}_{\mathrm{x}}\right)$ levels. Thus combustor designs must evolve that produce ultra-low levels of $\mathrm{NO}_{\mathrm{x}}$ such that no harm is done to the ozone layer while at the same time having high levels of combustion efficiency and operability across the mission profile.

\section{Airport Noise}

The other HSCT environmental barrier challenge that must be met is aircraft noise during 
takeoff and landing portions of the mission. Unlike the current subsonic aircraft fleet, the prime contributor to an HSCT noise signature at takeoff is the jet exhaust, and thus an approach to quieting the jet exhaust without seriously impacting propulsion system performance or weight must be developed. However, during landing. noise emanating from the fan also hecomes an important contributor along with the jet exhaust.

Any HSCT propulsion noise reduction approach pursued must take into consideration that a noise rule stricter than the current FAA FAR 36 Stage 3 may be in place by the time an HSCT would enter the fleet. Thus candidate approaches must be evaluated for potential to have even greater noise reduction than those currently required for certification of subsonic aircraft.

\section{Economic Challenges}

Solutions to the environmental challenges discussed above as well as the demanding performance requirements of supersonic cruise will require the use of many advanced technologies. However, the HSCT has the same constraints as any commercial aircraft design; the lechnologies employed in the design must improve the product but not at the expense of significantly increased costs (acquisition. operation, and maintenance). Clearly, for the HSCT to become a reality, it must be a profitable venture, both for the aircraft and engine manufactures, as well as for the airlines. The already mentioned market studies being conducted have in some cases involved surveys with the flying public. These surveys suggest that for the long haul, primarily over water routes across the Atlantic and Pacific Occans, travelers would be willing to pay as much as 20 to 30 percent more for tickets with the prospect of halving the travel time. The motivation to pay more for reduced travel time, not too surprisingly, increases as the travel time exceeds 4-5 hours. This information gives one some insight into what economic viability means for an HSCT in the view of the traveling public, who are the ultimate customers and will in part help determine what technologies will be included on the HSCT.

\section{System Requirements and Technology Drivers}

Figure I compares the Concorde, the world's only operational commercial supersonic aircraft, with the current perspectives on the HSCT. While the
Concor de remains an engineering marvel almost 30 years after its maiden flight, it achieved neither envirormental compatibility nor economic viability. Hence only 16 Concorde aircraft were ever built and 13 are currently in operation, serving selected trans Atlantic routes with fares several times higher than widebody subsonic aircraft. For the HSCT to become a reality, it is envisioned that the aircraft design must have at least the features depicted on the right half of this figure.

Translating these system level HSCT requirements shown on figure 1 into those for the HSCT propulsion system suggests that the engine manufacturers must design, build and certify an HSCT propulsion system that meets the following requirements. First, in order to achieve supersonic cruise vapability the propulsion system must have performance levels comparable to a supersonic military fighter ıngine. Second, to be acceptable to the general public, the HSCT propulsion system must contribute to meeting the environmental challenges of $\mathrm{NO}_{x}$ and community noise. The requirement to produce low $\mathrm{NO}_{x}$ rests solely with the development of new types of combustor designs. These stringent requirements compared to what is possible using current combustor technology are shown in figure 2 . However, this figure also shows that the solution to the HSCT noise challenge cannotle meet simply by improving a single component but will require a systems engineering approach. Contributions to the vehicle noise reduction will come from several sources including, advanced exhaust nozzles, engine cycle characteristics, advanced fans, advanced high-lift concepts and possibly advanced aircraft operational procedures such as programmed lapse rate.

Third an HSCT propulsion system must contribute to meeting the HSCT economic viability requirenents. The propulsion system must be light weight and demonstrate good efficiency in order 10 achieve a vehicle with sufficient range and payload to be an economic success. At the same time it must demonstrate durability and long life characteristics that ar 2 comparable with subsonic commercial propuls on systems. As shown in figure 2, the maximum cycle $t$ mperatures are comparable with those of existin! engines today. However, these temperatures must be maintained throughout the cruise portion of 
the mission rather than only at short segments of the flight such as takeoff. This results in a requirement for the engine to operate at the combined conditions of high temperature and high stress for 30 times longer than either subsonic transports or military fighters do today.

In addition, the HSCT propulsion system will be big, as figure 3 depicts. The overall length will be about 50 feet with a maximum diameter of about 50 inches. This overall propulsion system size will provide a significant design challenge for all components. As an example, figure 4 shows that the high pressure turbine disk for the HSCT is estimated to be about twice the size of the disks found in current subsonic transports.

\section{Technology Development Accomplishments}

As discussed above, the technology challenges related to environmental compatibility and economic viability for the HSCT propulsion system and indeed for the whole vehicle are tremendous. Clearly the HSCT engine designers will not be able to meet these challenges with currently available propulsion technologies. As is shown in figure 5, NASA began the HSR Program in FY 1990 in order to address these technology shortfalls both for the airframe and the propulsion system. Since its inception, the HSR Program has had as a vision the development and transfer of the high risk, high payoff technologies to industry, which in turn would be able to make a lower risk product launch decision at the time when all the factors contributing to a commercial aircraft launch are considered. The HSR Program was constructed so as to first address the environmental challenges (Phase I) and only if there were viable solutions developed for NOx and noise reduction would the Phase II program be initiated. The Phase Il Program would have as its emphasis the development of the highest payoff technologies associated with economic viability.

To date, the propulsion element of the HSR Program has enjoyed considerable technical success. In Phase I, viable laboratory solutions for the environmental challenges were developed and demonstrated. In Phase II, which is currently being executed the propulsion technologies for the critical components, including advanced high temperature engine materials are being successfully transitioned from the laboratory to the larger scale component designs. These components will be tested and evaluated in severe realistic engine environments. Figure 6 overviews the propulsion element content of the Phase I and II efforts of the HSR Program.

Progress has also been significant in the airframe element of the HSR Program. Specifically, advanced high lift approaches have been developed and demonstrated in model scale along with improved supersonic performance planform configurations and advanced composite materials for the airframe structure which are capable of withstanding up to the $350^{\circ} \mathrm{F}$ temperatures that the HSCT will encounter during supersonic cruise. In addition, concepts for advanced flight deck designs have been evolved utilizing synthetic vision which offer possibilities for increased levels of aircraft safety beyond those available today.

The remainder of this paper will overview some of the technology advancements being made by the propulsion element of the HSR Program.

\section{Technology Concept Propulsion System}

Since the HSR Program is a focused technology program driven by vehicle requirements (including the propulsion system), it is necessary to have a technology concept aircraft to focus the technology development efforts so as to make informed decisions about which technologies to pursue and which can be discarded. either being too risky to pursue or having too little pay off to merit investment of critical resources. In 1996, a technology concept aircraft was developed by the NASA/ industry team along with a technology concept propulsion system as depicted in figure 7 . This "paper propulsion system" was configured after incorporating the results of over 12,000 hours of scale combustor, nozzle, and inlet tests, over 50,000 hours of engine materials testing. and over 250 work years of propulsion and airframe systems studies. The technology concept propulsion system will continue to serve a critical role in the remaining years of the HSR Program as it will enable NASA and industry personnel to evaluate individual component and subcomponent technologies against the overall system requirements.

Figure 8 lists some of the major technology advances made for the various components of the HSCT propulsion system. These will be briefly reviewed in the following paragraphs. 
Inlet

A series of subscale (approximately 25\% HSCT scale) supersonic wind tunnel tests have been conducted of candidate axi-symmetric and two dimensional mixed compression configurations. All tests were conducted in the NASA Lewis Research Center (LeRC) 10x10 Supersonic Wind Tunnel to evaluate supersonic performance and isolated component operability. These test results along with a systems evaluation and a relative risk assessment of the candidate inlets were used to make an HSR Program down-select to a two dimensional bifurcated configuration. Figure 9 shows a two dimensional inlet test configuration in the $10 \times 10$ SWT. To date all tests have been coldpipe tests, that is they did not involve engine testing. Future tests will involve using a GE J85 turbojet engine to examine inlet-engine operability requirements.

In addition. a large-scale, simulated inletengine operability test was conducted in Russia as part of the US/Russia TU-144 program. Figures 10 and 11 show the overall setup and a close-up of the simulated supersonic inlet flowpath. The engine used for these experiments was an RD 36-51 A which was used on the original TU144 aircraft. These test results are giving the NASA and industry personnel added insight into some of the important design features for the subsonic diffuser of the HSCT inlet and in particular how close coupled the inlet and fan can be without adversely affecting performance and operability. Reference 6 gives added information on these highly successful international test efforts.

\section{Combustor}

A large number of flame tube (figure 12) and subscale sector (figure 13) tests of candidate ultra-low NOx combustor configurations have been tested in NASA and industry facilities since the HSR Program began in 1990. Tests have been conducted of both Lean Premixed-Prevaporized (LPP) and Rich Burn/ Quick Quench/Lean Burn (RQL) configurations. Both flame tube and sector test results have been promising, with NOx results being measured in the El range of 2$7 \mathrm{gm} \mathrm{NOx/kg}$ fuel being measured. A combustor down-select will occur in 1998 and the most promising configuration will then be evaluated in both full size sector and full annular rig testing in the remaining years of the HSR Phase II Program.
The HSCT combustor cannot rely on conventional wall film cooling techniques if ultralow levels of NOx are to be achieved. The HSR Program has been developing a Ceramic Matrix Composite (CMC) material from which a combustor liner conld be designed that would require only backside cooling. Initially a number of candidate fibers, matrices and processing techniques were evaluated, but in 1996 an SiC based CMC was selected which incorporates a melt infiltration processing technique. As figure 14 shows, the HSR Program has been very successful in taking this material from the laboratory to fabricating complex three dimensional shapes more representative of a combustor liner. Durability tests are currently underway to evaluate material performance in the oxidizing and reducing environments of an HSCT combustor. Recognizing the risks associated with a CMC liner material, the program is evaluating a metallic liner with thick thermal barrier coating as a backup approach. A liner material down-selection will occur in 1999 and the selected naterial will be evaluated in a full annular combust ir rig test.

\section{Nozzle}

Like the combustor, a large number of small scale (approximately $1 / 7$ to $1 / 10 \mathrm{HCST}$ scale) nozzle configurations have been designed and tested to evaluate the most promising approaches for significant reductions in noise associated with the exhaust jet at both takeoff and landing conditions, while at the same time maintaini g high levels of aerodynamic performance (i.e., thru; coefficient) at low speed conditions. The HSCT nozzle design must be a balanced one that addresses both aerodynamic and acoustic requirements simultaneously. Many of the tests have been dedicated to acquiring fundamental data so that the underlying physics o the nozzle internal flowfield and especially the mixing region are will understood.

ligure 15 is an example of an early configurition tested in the Bocing Low Speed Aeroacoustics Facility (LSAF). The small scale test results have been most encouraging as sideline noise levels at iakeoff conditions below 100 EPNDB have heen mea ured, which compares to a 120 EPNDB level measured for the Concorde. Based upon not only the many thousands of hours of test data. but also the supportin y airframe and propulsion system studies, the NASA/in lustry team selected the mixer-ejector nozzle as the app oach that of fered the greatest potential for the 
HSCT application. Successive generations of small scale tests are continuing to pursue mixer-ejector configurations that promise additional noise reduction and improved aerodynamic performance.

In addition to the isolated nozzle tests, the impact of the airframe on the mixer-ejector nozzle performance (aerodynamic and acoustic) has been evaluated through tests conducted in the NASA Ames National Full Scale Aerodynamic Complex (NFAC) as shown in figure 16 . This 13.5 percent half plane model test results have given the US team confidence that the integration effects can be minimized. Recently, the first of a series of large scale model tests was completed.

Advanced materials systems are critical to all aspects of the design of a variable HSCT nozzle system. Specifically the nozzle must demonstrate acceptable aero/acoustic performance, weight and durability. A number of candidate materials systems have heen evaluated through a variety of design, fabrication test and analysis activities. Based on this comprehensive database and the airframe and propulsion system studies, materials down-selects were recently completed, as depicted in figure 17. Emphasis in the HSR Program is now turning to refining the fabrication and scale-up approaches selected for each of the nozzle sub-components and evaluating these technologies in benchmark tests to be conducted at NASA LERC.

A series of large scale nozzle model tests of the most promising configurations have recently begun. These tests will evaluate both aerodynamic and acoustic performance at low speed conditions for the approximately $60 \%$ scale models. Figure 18 shows the first Large Scale Nozzle test configuration on an outdoor test stand at Pratt \& Whitney. A Pratt \& Whitney F- 100 engine was used to provide realistic flow conditions into the nozzle. The comprehensive large scale data base obtained from these tests will provide insight of the effects on both aerodynamic and acoustic performance of scale, as well as the realistic engine environment. In addition, major subcomponents using the down-selected materials and fabrication techniques are being included in these tests to evaluate their performance in the hostile engine environment. For example, ceramic matrix composite (CMC) acoustic tiles and ceramic bulk absorbers were successfully tested in the recently completed large scale nozzle tests.

\section{Turbomachinery}

Only selected technology areas of the engine turbomachinery that are critical to the future success of an HSCT propulsion system are being tested under the HSR Phase II Program. These technology areas are the fan, disk materials and turbine airfoil systems.

The multi-stage fan design required for the HSCT propulsion system is vastly different from what is currently used in the subsonic fleet. As a result, very little is known about the acoustic signature of this type of fan. Therefore, work is underway to design, fabricate and test a subscale fan and inlet combination in the NASA LeRC $9 \times 15$ Wind Tunnel. This test will provide valuable acoustic data to substantiate models of the fan source noise as well as the noise attenuation in the inlet. This insight into the fan acoustic characteristics will be used in conjunction with the nozzle acoustics to mitigate the risk of meeting the landing and takeoff noise challenges faced by the HSCT.

The extended time at temperature requirements of the HSCT requires that the disks for both the compressor and turbine have a critical balance of tensile, fatigue and creep strength as well as fatigue crack growth resistance. These requirements exceed the capabilities of any of the available Nickel based superalloys. The HSR Program has evaluated a large number of experimented alloys (figure 19) and identified promising candidates which have met the HSR Program goals. as the figure suggests. Emphasis is now turning to taking these most promising alloys and evaluating the scale-up approaches for forging and heat treatment that maintain the critical performance characteristics. Appropriate subcomponent tests will be conducted as the final technology validation efforts for the HSR Program.

The materials system for the turbine airfoil system really consists of three components-a single crystal Nickel based airfoil superalloy, a bond coat, and a thermal barrier coating. Significant progress has been made in the HSR Program to date on developing experimental alloys that are significantly better than those currently available for production 
applications (figure 20). A new thermal barrier coating system is being developed to meet HSCT life goals. Progress to date includes identification of new bond coat and ceramic compositions. Emphasis in the remaining years of the HSR Program will be to combine the three components into a turbine airfoil design and demonstrate technology readiness through appropriate rig tests.

In addition to the technology development in the fan, disk and turbine airfoil, Conceptual Mechanical Design Studies of the entire engine have been ongoing in the HSR Program. These studies ensue that the technologies that are being developed in the key areas discussed above can be brought together into a viable propulsion system that will meet the environmental and economic challenges faced by the HSCT.

\section{Future Plans}

The current HSR Phase 11 effort is primarily aimed at developing critical technologies at the component level and demonstrating these technologies through scale component tests. To provide additional risk reduction beyond this Phase II effort, the HSR Program is planning a Full-Scale Engine and Nozzle Technology Demonstrator project. This follow-on project would validate, through full-scalc engine/nozzle tests, the technologies that contribute to overall HSCT environmental compatibility as well as the overall system goals for performance and operability.

In addition, this project will demonstrate appropriate HSCT Accelerated Mission (AM) test techniques to assess full-scale engine/nozzle component durability for the HSCT duty cycle and will include the evaluation and understanding of the long-term durability of structural materials with respect to metallurgical changes resulting from $\mathrm{HSCT}$ long-hot-time design requirements. and the use of economically feasible, large-scale manufacturing techniques.

\section{Concluding Remarks}

NASA's High-Speed Research Program has been formulated to provide the US industry with the critical technologies needed to support an informed decision by industry as to whether to launch an HSCT early in the next century. The financial risk to launching an HSCT without adequately mature and proven technologies in hand is enormous. Industry estimates indicate that it will cost at least \$13-15 billion to design. build and certify an HSCT once the decision to launch is made. While such amounts seem incredibly large, the financial returns estimated for a fleet of 500-1500 aircraft also must be considered. Industry estimates for such a fleet (including the initial aircraft as well as spare parts and maintenance) project that $\$ 200$ billion in sales may be realized. Thus it appears that the product launch of an HSCT will be a major decision for the commercial aerospace industry to make which will have financial implications that will be far reaching.

To date the HSR Program has provided industry with the high risk, high payoff airframe and propulsion technologies that support the vision of an HSCT becomirg part of the $21^{\text {st }}$ century international air transportation system. However, the maturity of these technologies, sometimes called the Technology Readiness Level (TRL) by NASA is still much too low for industry to consider the risk of a product launch decision as being acceptable. It is therefore critical that the HSR Program continue to successfully mature these technolegies and transfer them to industry to contribute to reducing the risk of a product launch decision to acceptable levels.

\section{$\underline{\text { References }}$}

1. "High-Speed Civil Transport Study," NASA CR $423 ., 1989$.

2. "Study of High-Speed Civil Transports," NASA CR 4235, 1989

3. "Con mercial High Speed Aircraft Opportunities and ssues," Congressional Research Service Repcrt 101 14, March 1989

4. Current market Outlook-1994: World Market Dem ind and Airplane Supply Requirements. Boeing, Seattle, WA 1994.

5. "Higl -Speed Transport Aircraft," Final Report of the IJASA Aeronautics Advisory Committee by the lligh-Speed Transport Aircraft, ad hoc Rev ew Team. Dec. 1989.

6. Acosea, W. A.; Balser, J. S.; McCartney, T. P.; Richter, C. A.; and Woike, M. R.: Joinı US/Russia TU-144 Engine Ground Tests, NASA TM107516, 1977. 


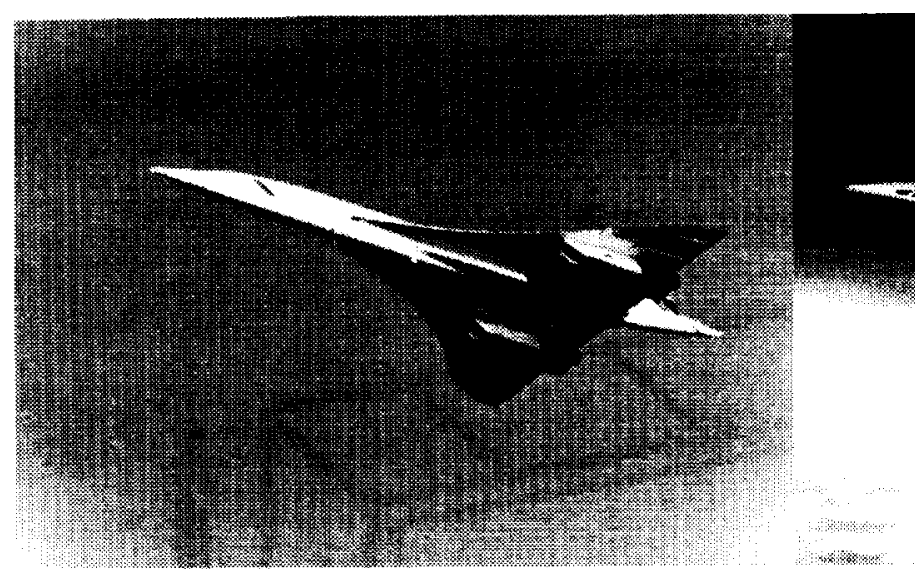

Concorde

3000
128
400,000
Exempt
Premium

20
Range (nmi)

Payload (passengers)

Weight (lb)

Community Noise Standard

Fare Levels

Emissions Index

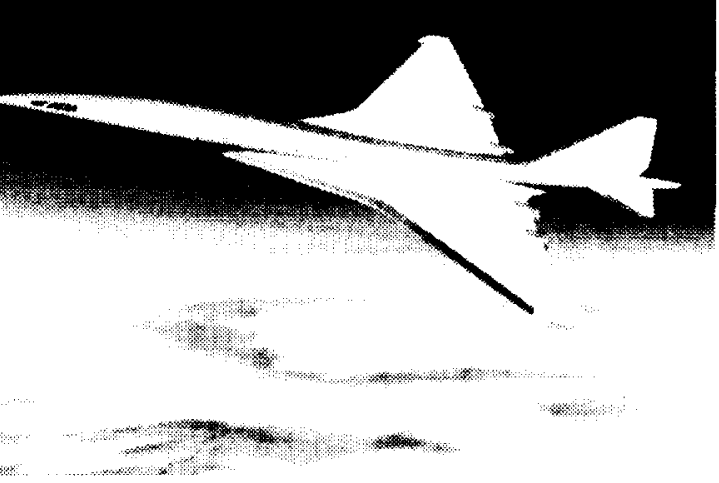

HSCT

\section{0 to 6500}

250 to 300

750,000

FAR 36 Stage III - XdB

Standard $+\leq \mathbf{2 0 \%}$ premium

5

Figure 1.-Comparison of Concorde to High Speed Civil Transport.

\section{EMISSIONS}

A Mach $2.4 \mathrm{HSCT}$ will cruise at altitudes coincident with the highest concentration of atmospheric ozone. Unconventional combustors are required to reduce $\mathrm{NO}_{x}$ emissions to levels which have no significant impact on the Earth's ozone layer.

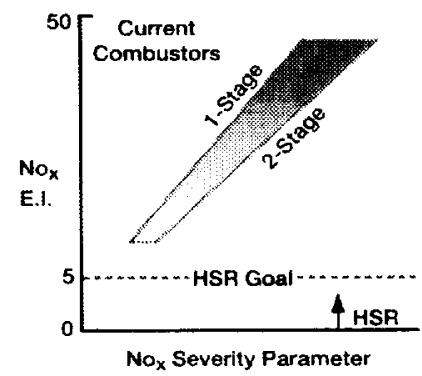

This challenge requires novel combustors and adv. materials.

\section{NOISE}

High specific thrust engines optimized tor supersonic cruise have high jet velocities and are inherently noisy. Unconventional engines/nozzles are required to achieve compliance with FAR 36 Stage 3 noise regulations while providing acceptable subsonic and supersonic cruise performance.

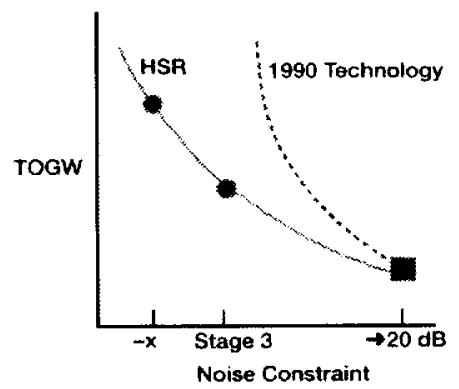

This challenge controls inlet engine nozzle selection.

\section{DURABILITY}

Over their entire life, current tactical fighter and subsonic commercial transport engines accumulate 250300 hours at max cycle temperatures and stress levels. HSCT propulsion systems must operate at these conditions for 9,000 hours. Thus, the HSCT duty cycle is $30 \mathrm{X}$ that of current engines.

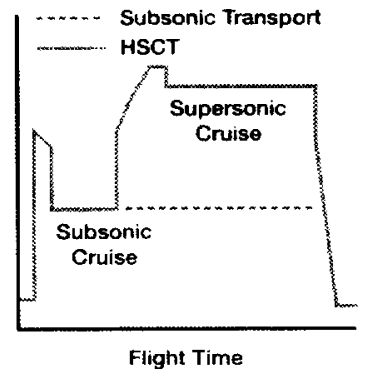

This challenge demands advanced high-temp materials and cooling schemes.

Figure 2.-HSCT propulsion system technical challenges. 


\section{HSCT propulsion systems are big engines}

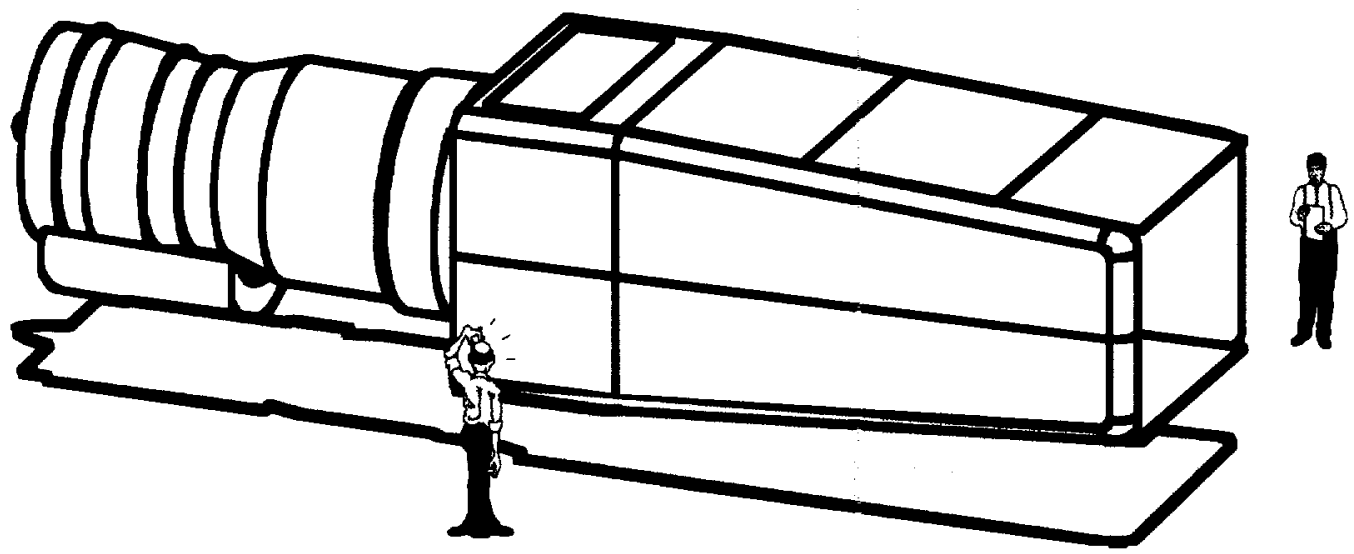

Figure 3.-Artist's concept of the full-scale HSCT propulsion system.

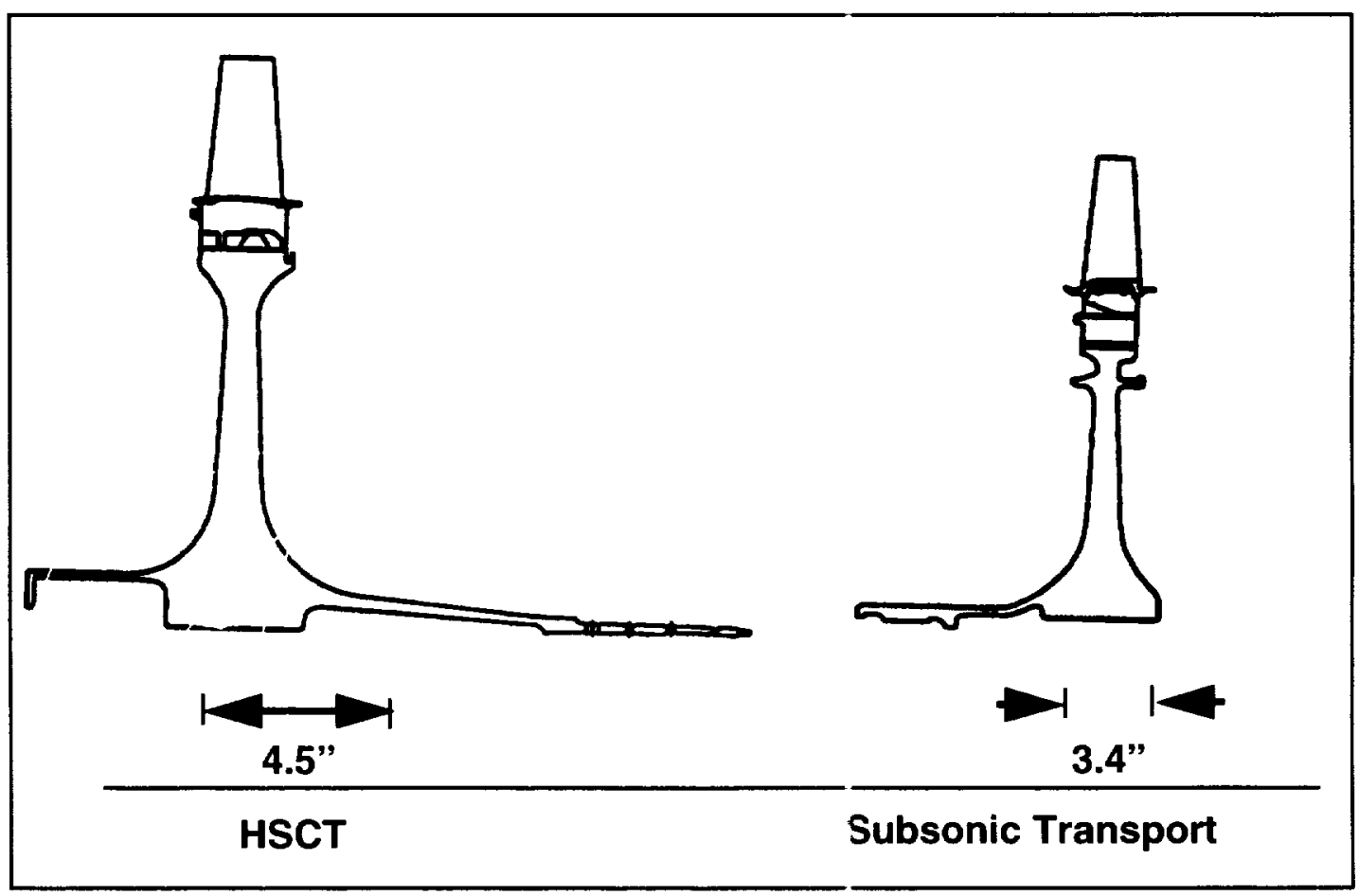

Figure 4.-Comparison of High Pressure Turbine disk sizes for HSCT and Subsonic Transport propulsion systems. 


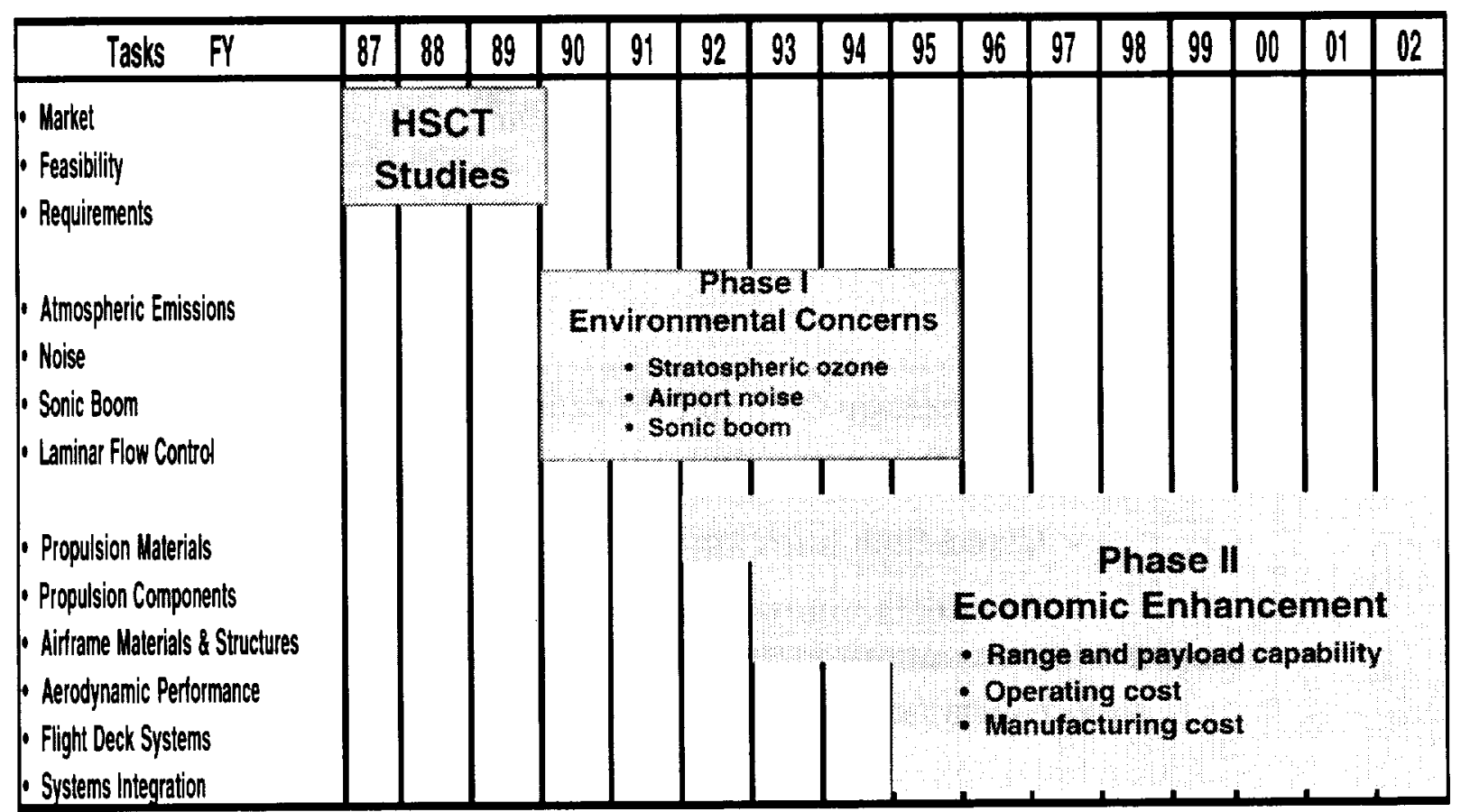

Figure 5.-NASAlndustry High-Speed Research Program.

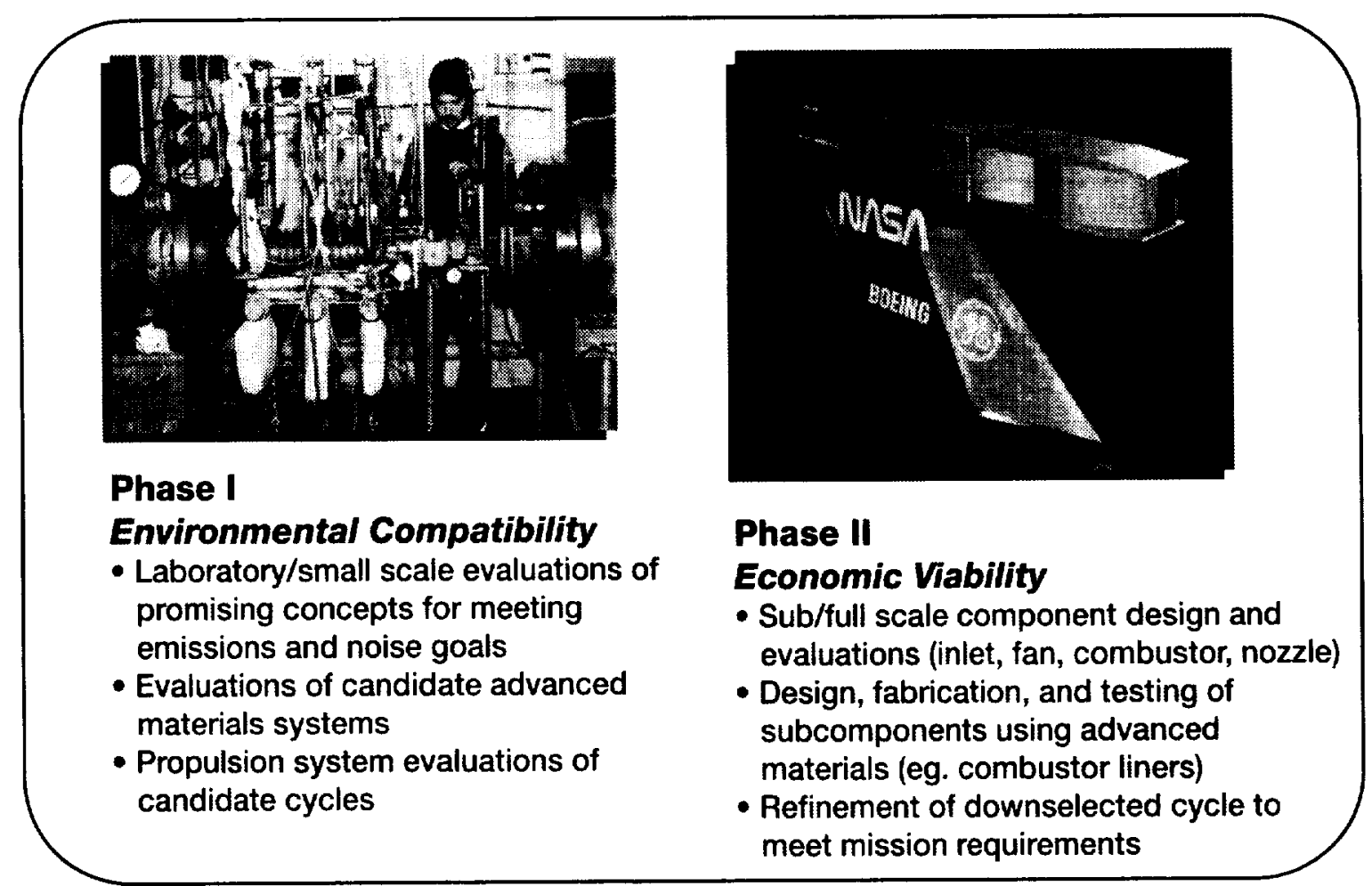

Figure 6.-High-Speed Research Program (Propulsion Element). 


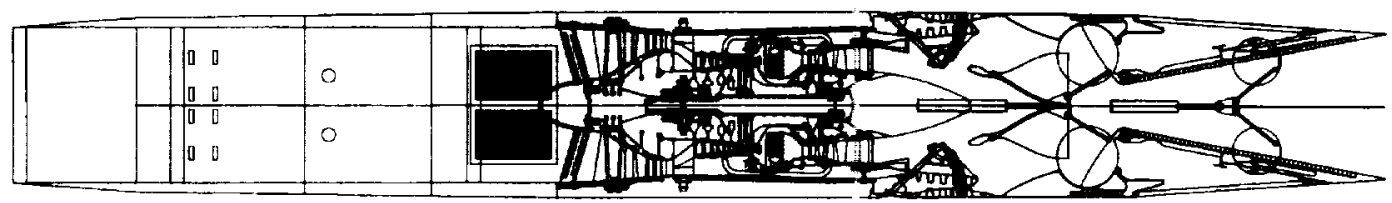

HSR Technology Concept Propulsion System

- Two-dimensional inlet

- Mixed-flow turbofan cycle

- Two-dimensional mixer-ejector nozzle

Figure 7.-HSR Technology Concept Propulsion System.

- Completed initial subscale flame tube anc sector tests for a variety of Lean Pre-mixed, Pre-Vaporized (LPP) and Rich Burn, Quick Quench, Lean Burn (RQL) concepts and demonstrated ultralow $\mathrm{NO}_{\mathrm{x}}$ potential of both approaches.

- Developed a CMC material which shows great promise for use as HSCT combustor liner which meets environmental and economic requirements.

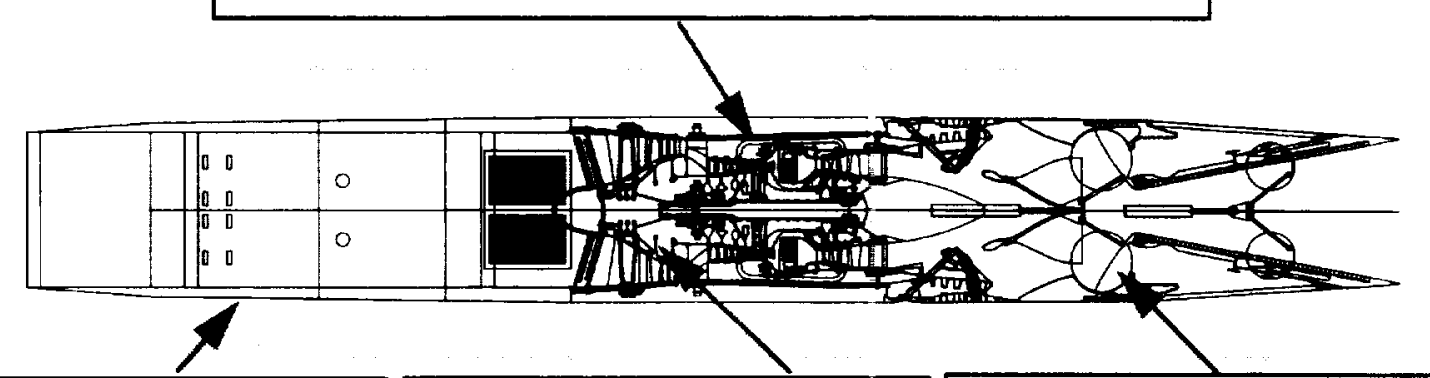

- Completed subscale tests of candiate axisymmetric and two-dimensional concepts.

- Completed large-scale inlet/engine operability tests as part of U.S /Russia TU 144 program.
- Developed experimental alloys for turbomachinery disk and turbine airfoil applications which show promise of meeting HSCT design requirements.
- Completed initial small-scale nozzle tests of configurations which meet aerodynamic and acoustic performance goals. Have identified approaches for further performance improvements.

- Completed evaluation of candidate materials systems for nozzle and demonstrated fabrication scale-up capabilities.

Figure 8.-HSR (propulsion) major technology advancements. 


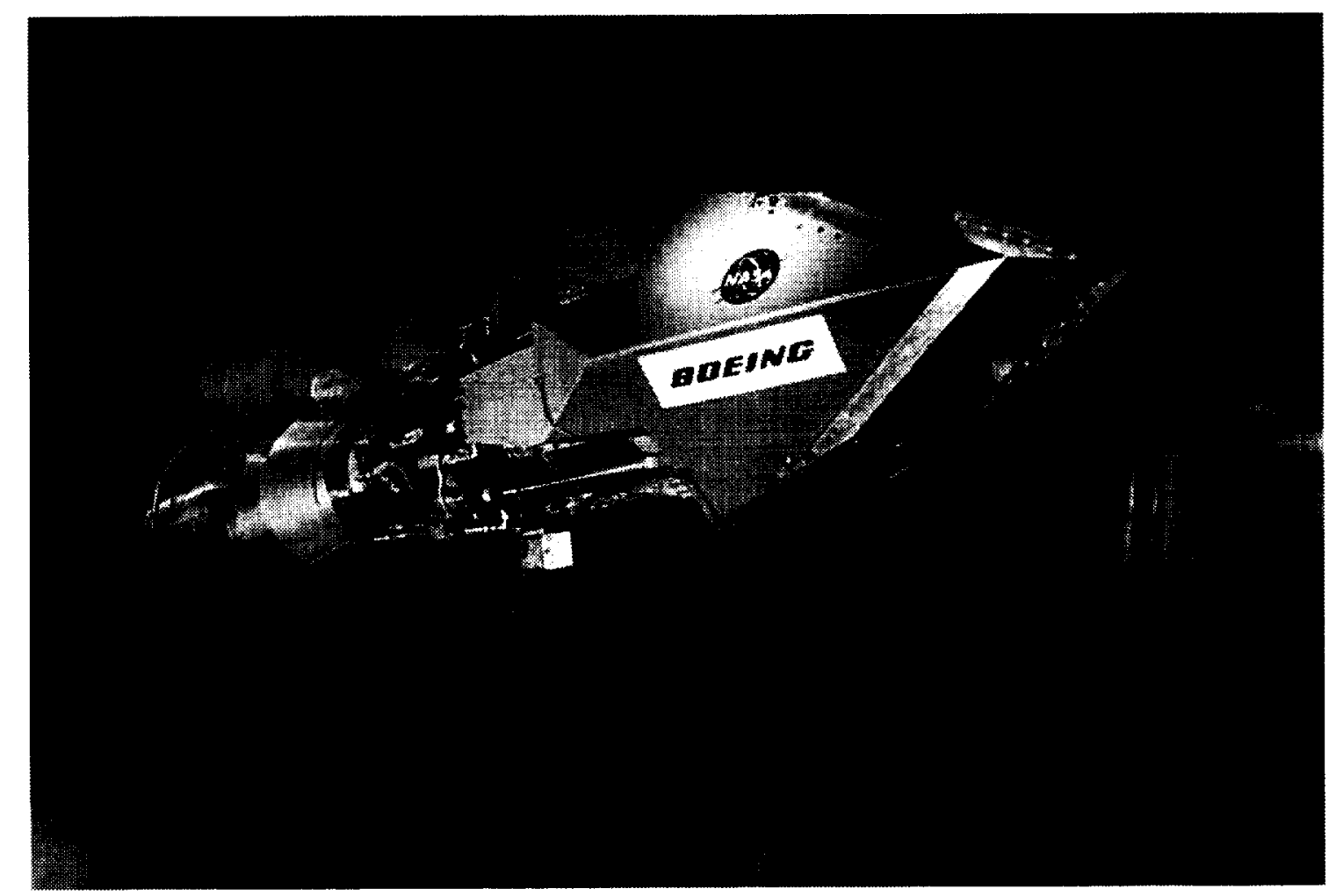

Figure 9.-Two-dimensional inlet test in NASA Lewis 10- by 10-Foot Supersonic Wind Tunnel.

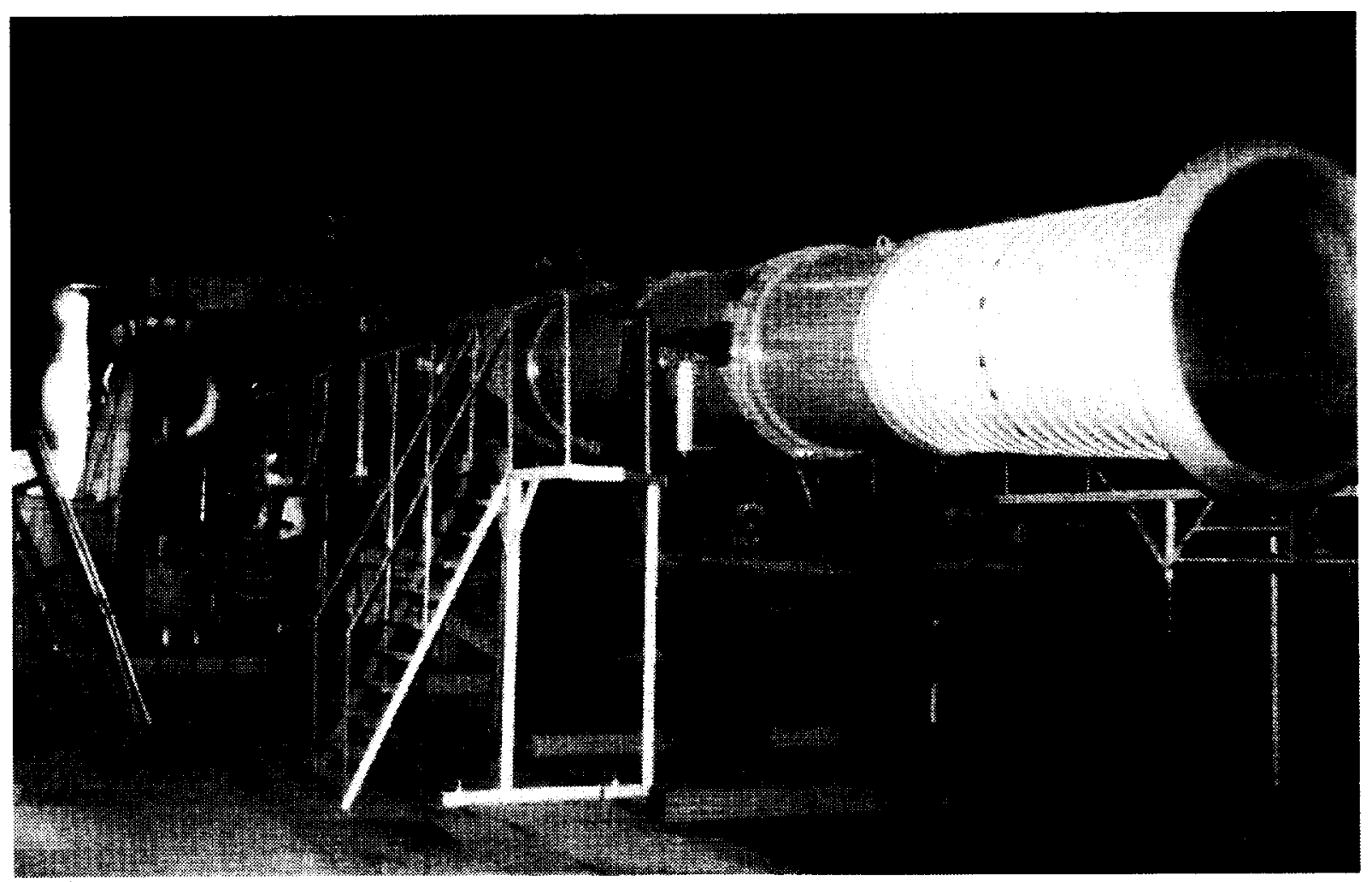

Figure 10.-U.S./Russia TU 144 engine ground test setup. 


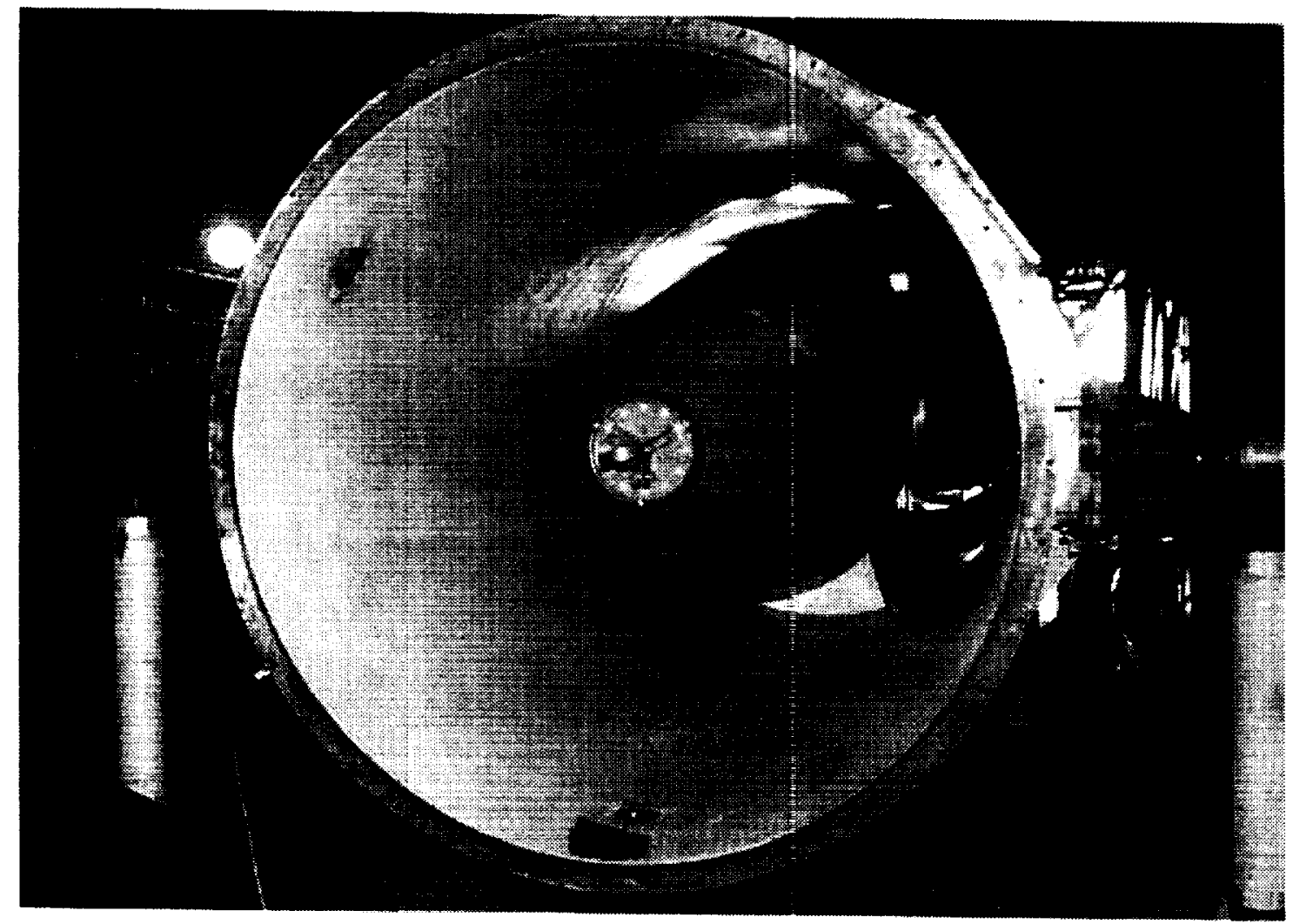

Figure 11.-Closeup view of simulated supersonic inlet flowpath.

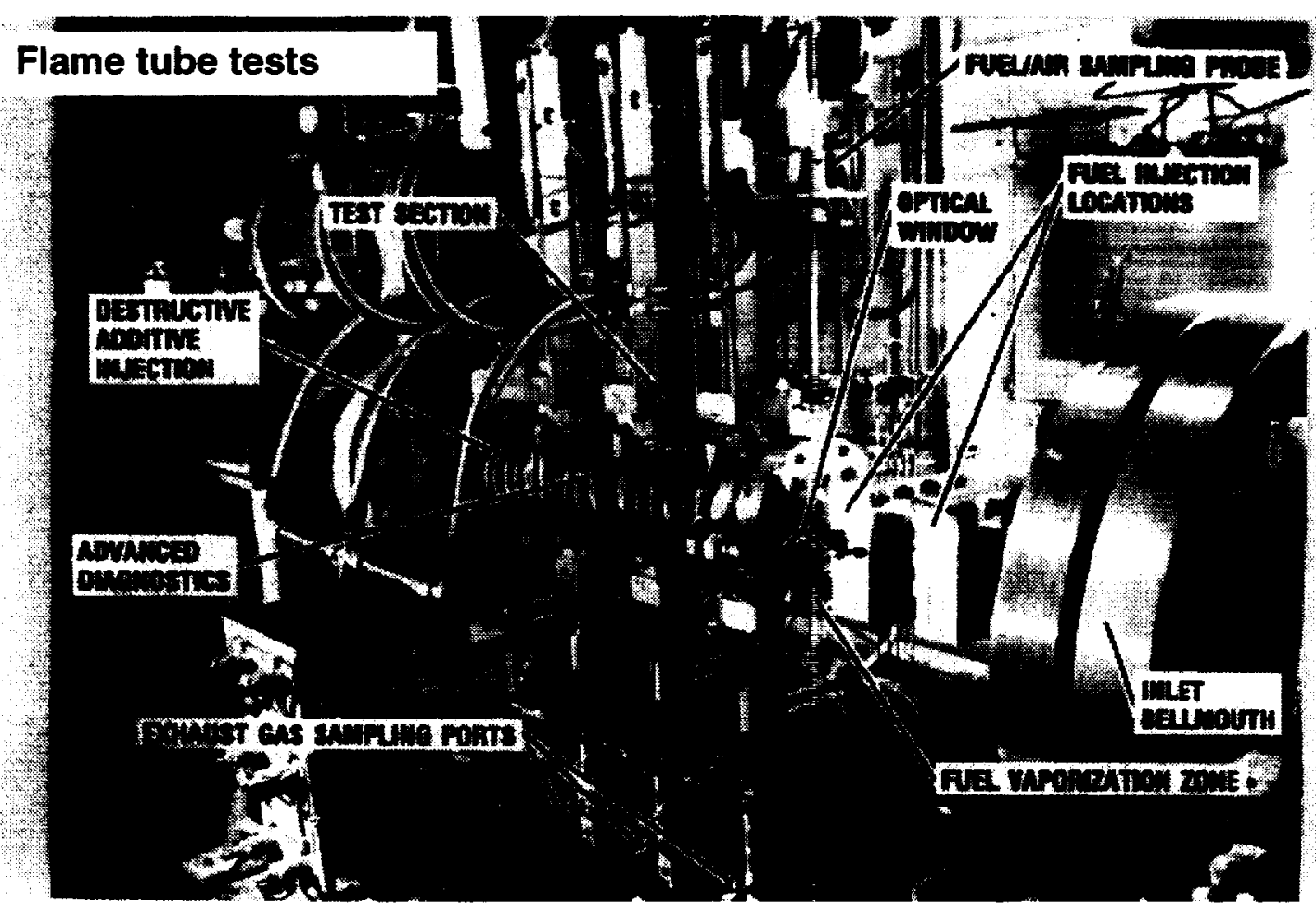

Figure 12.-Combustion flame tute test setup. 


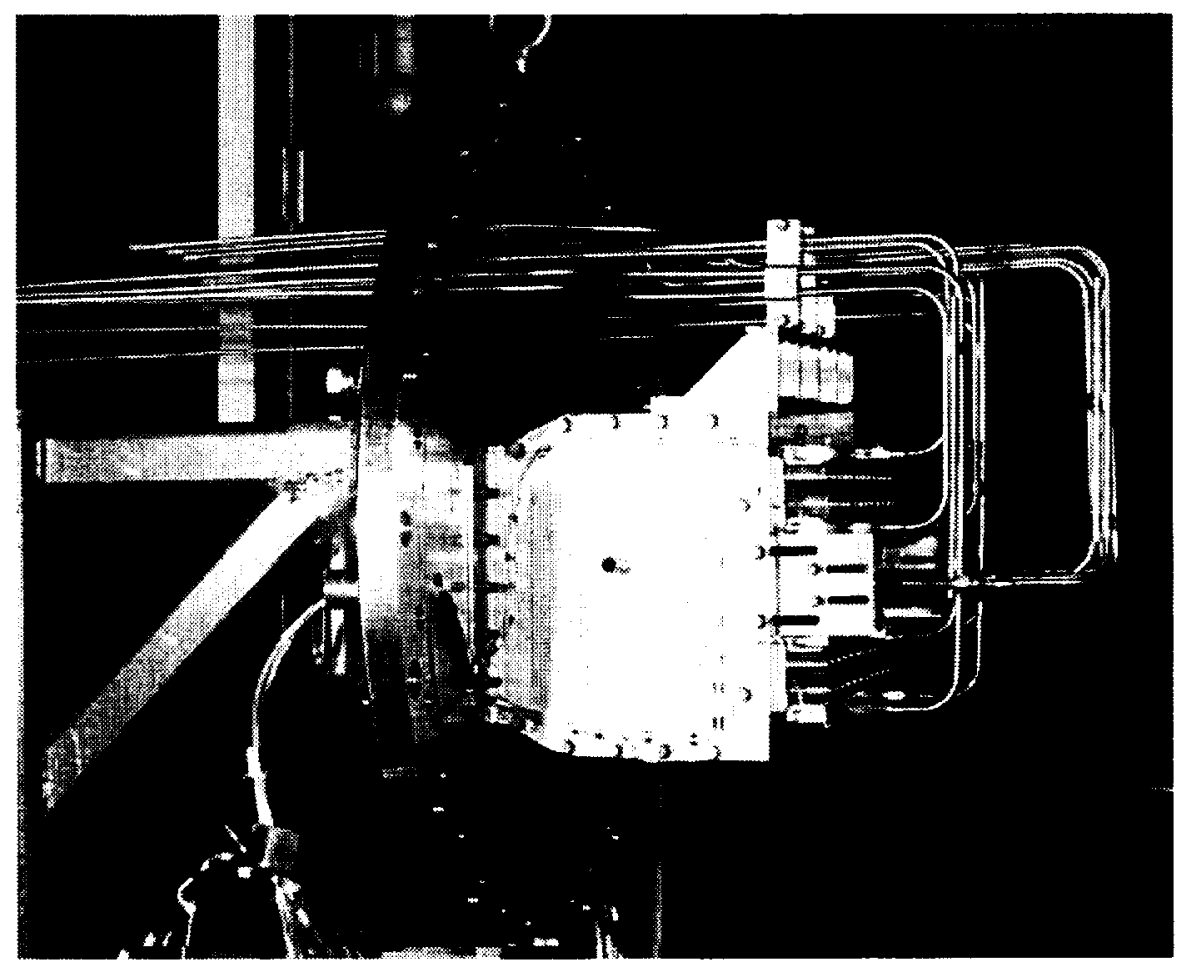

Figure 13.-Combustor sector test setup.

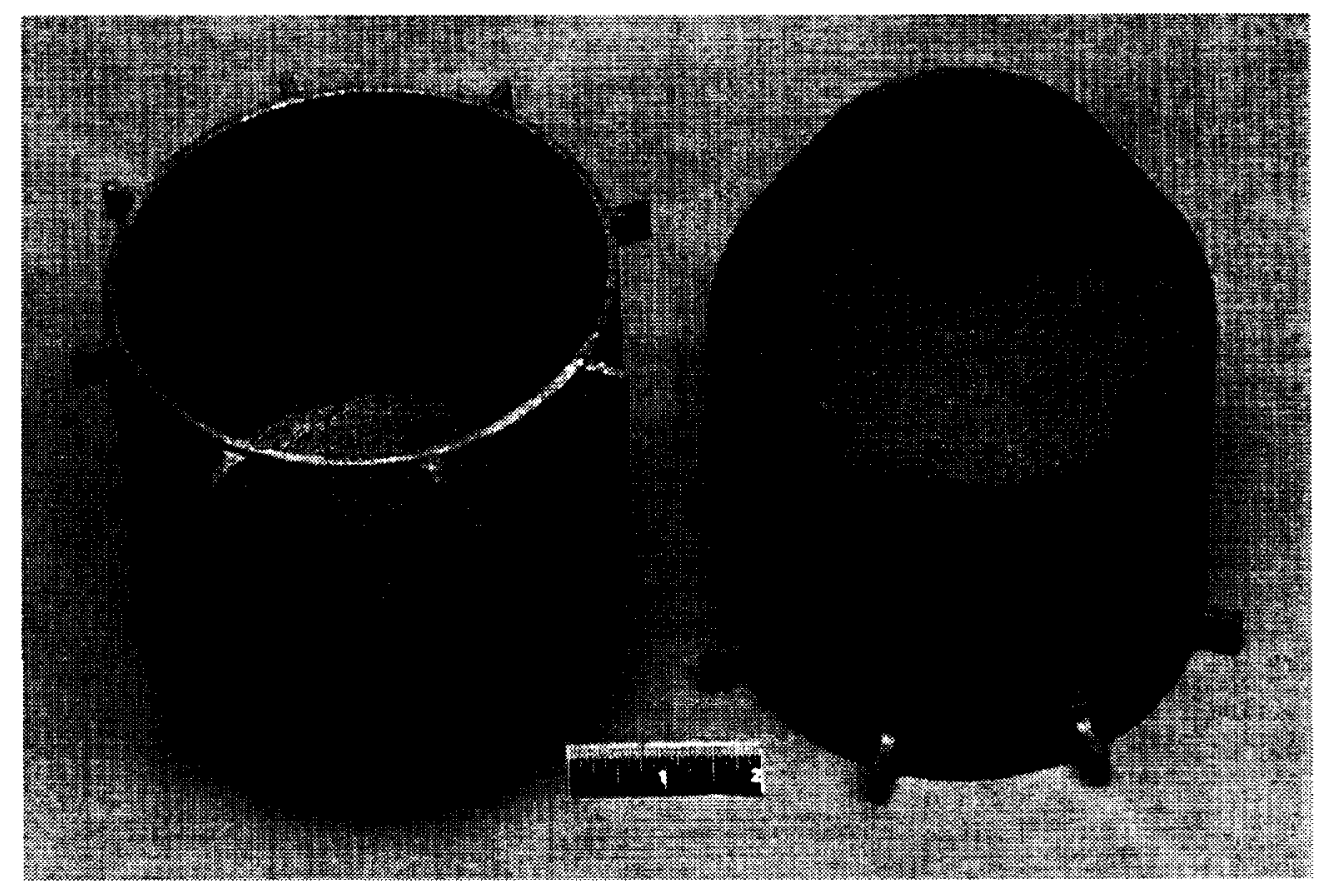

Figure 14.-Fabrication of complex shape from SiC-based ceramic matrix composite. 

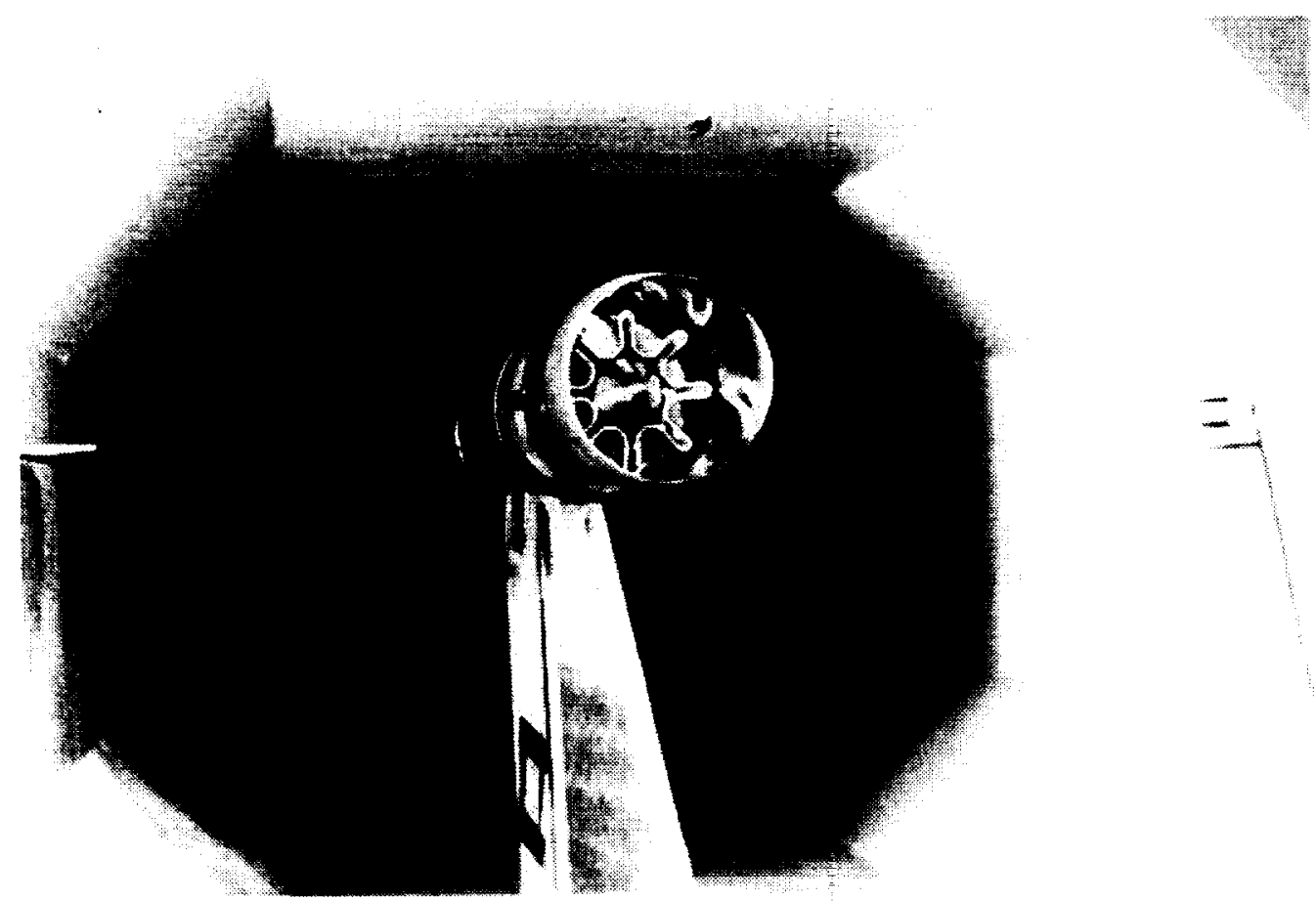

Figure 15.-Nozzle subscale tests setup.

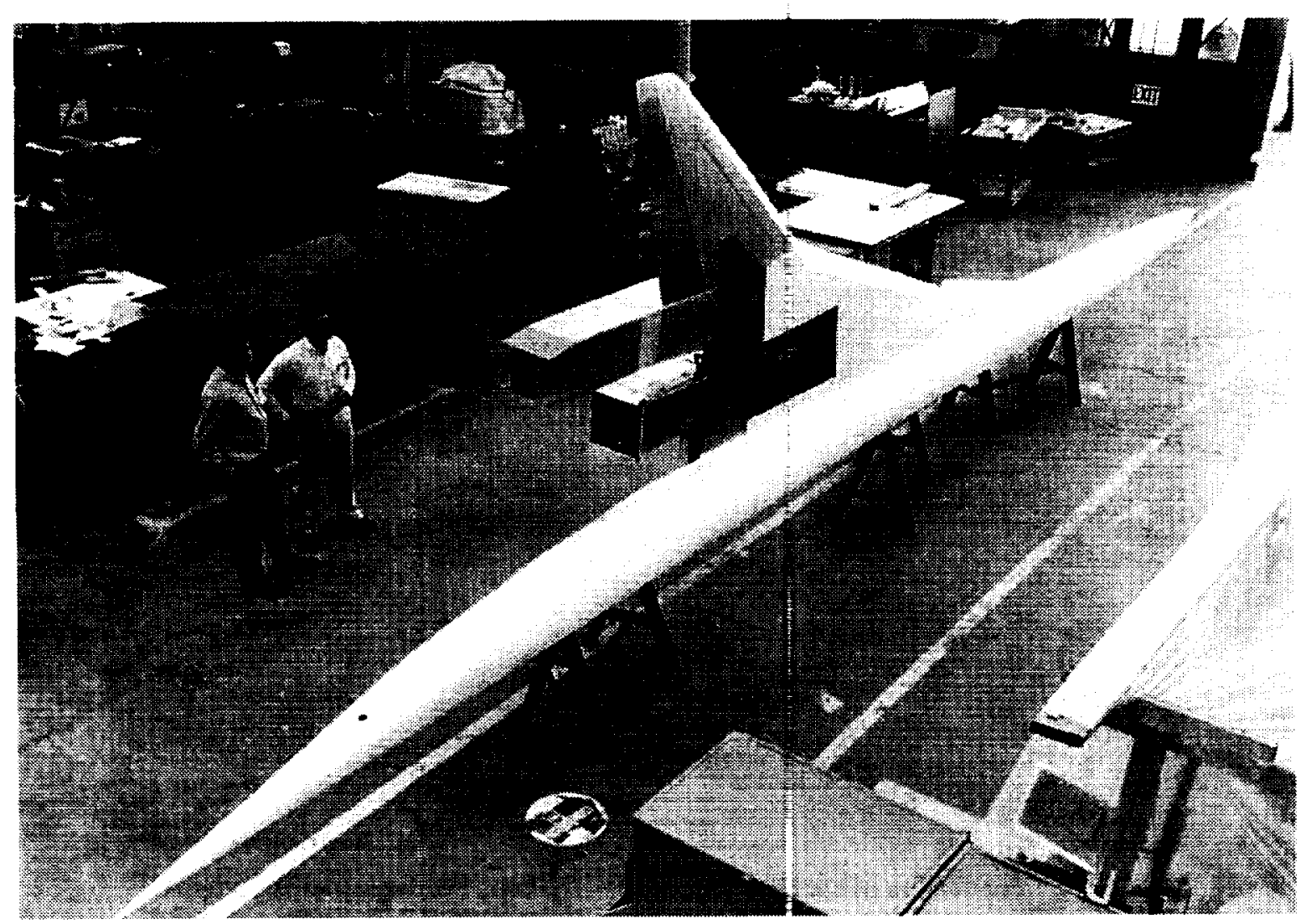

Figure 16.-Propulsion airframe integration test model. 


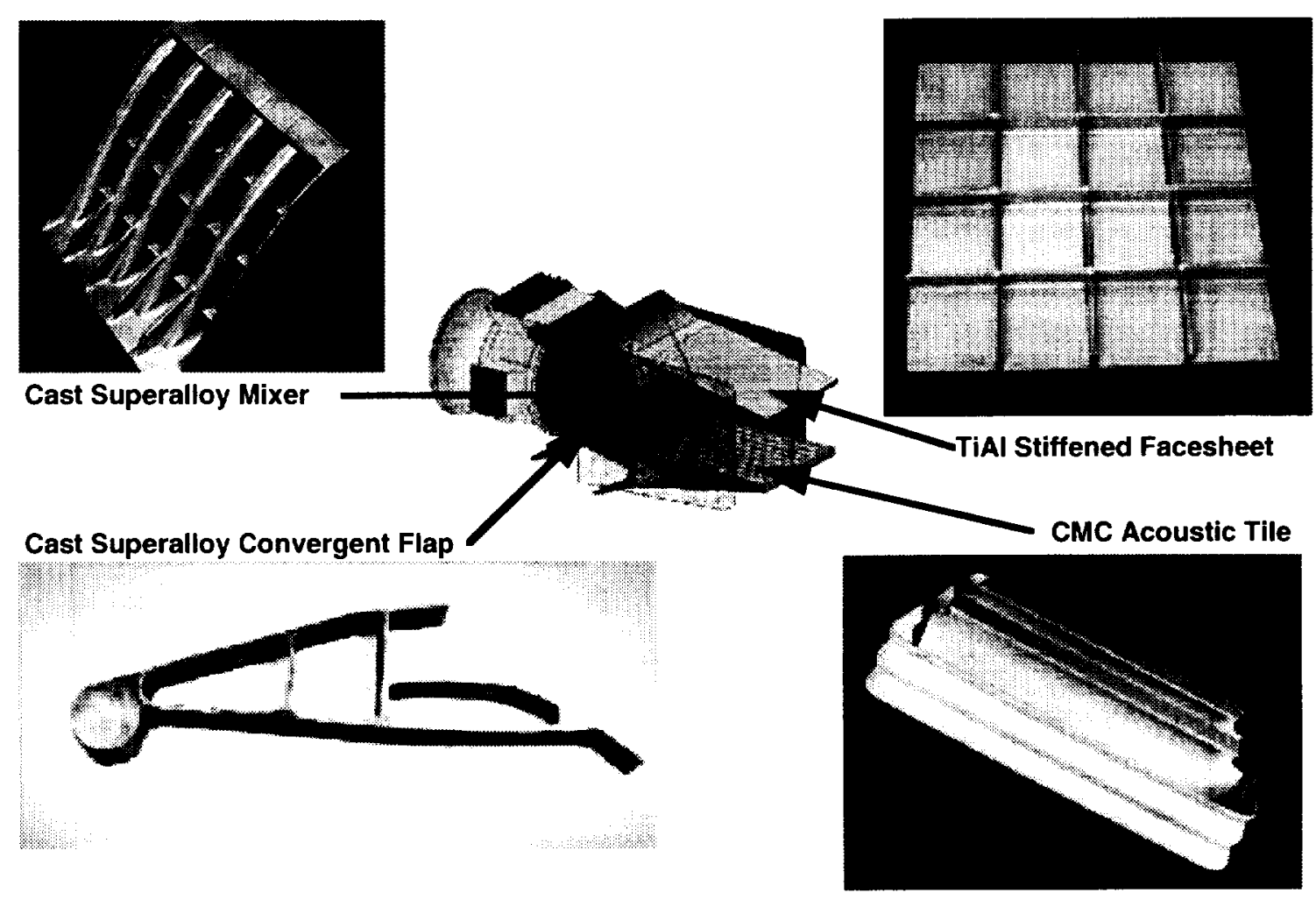

Figure 17.-Exhaust nozzle subelements fabricated for testing.

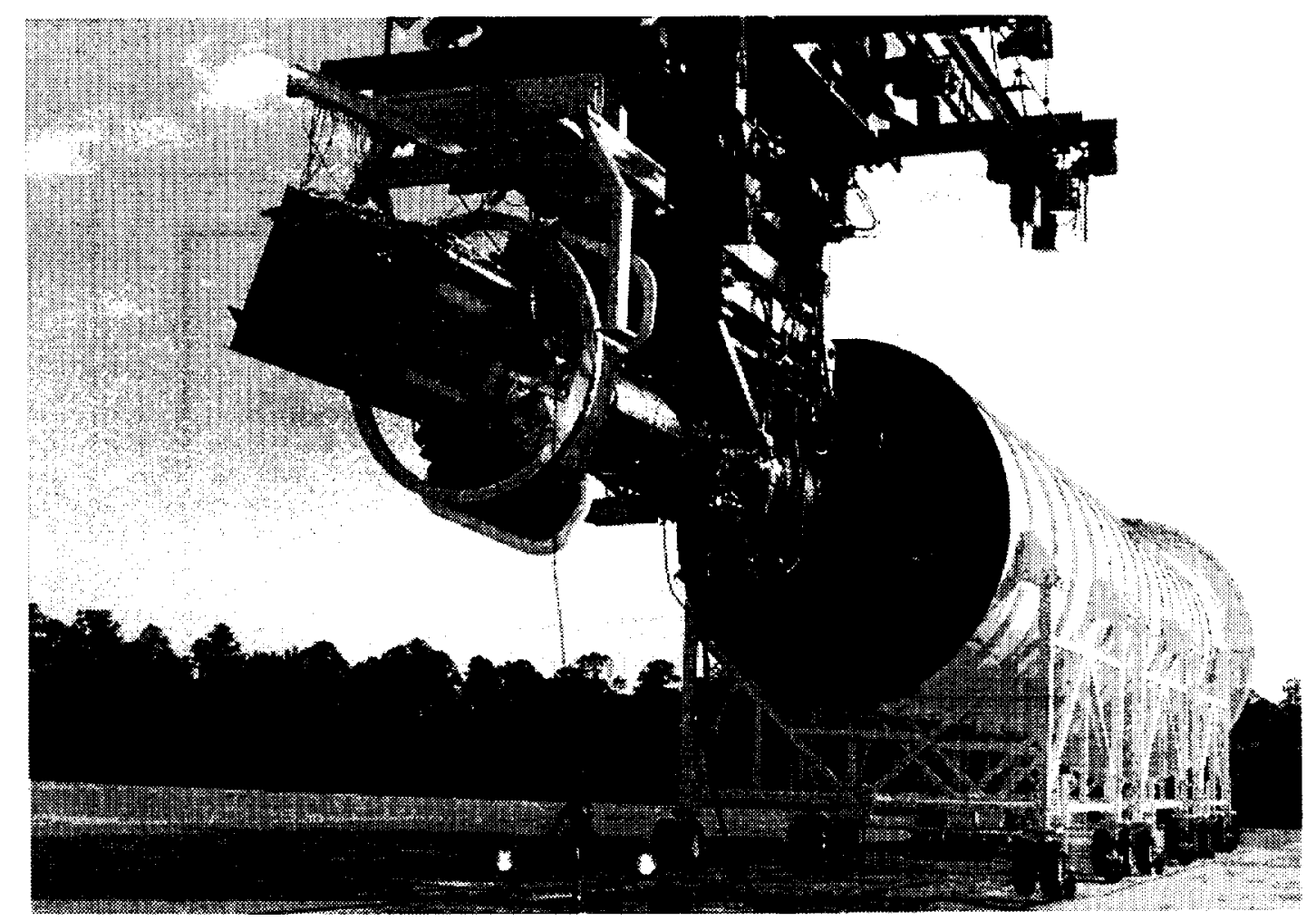

Figure 18.-Large-scale model nozzle test. 
HSCT disk airfoil alloy developed

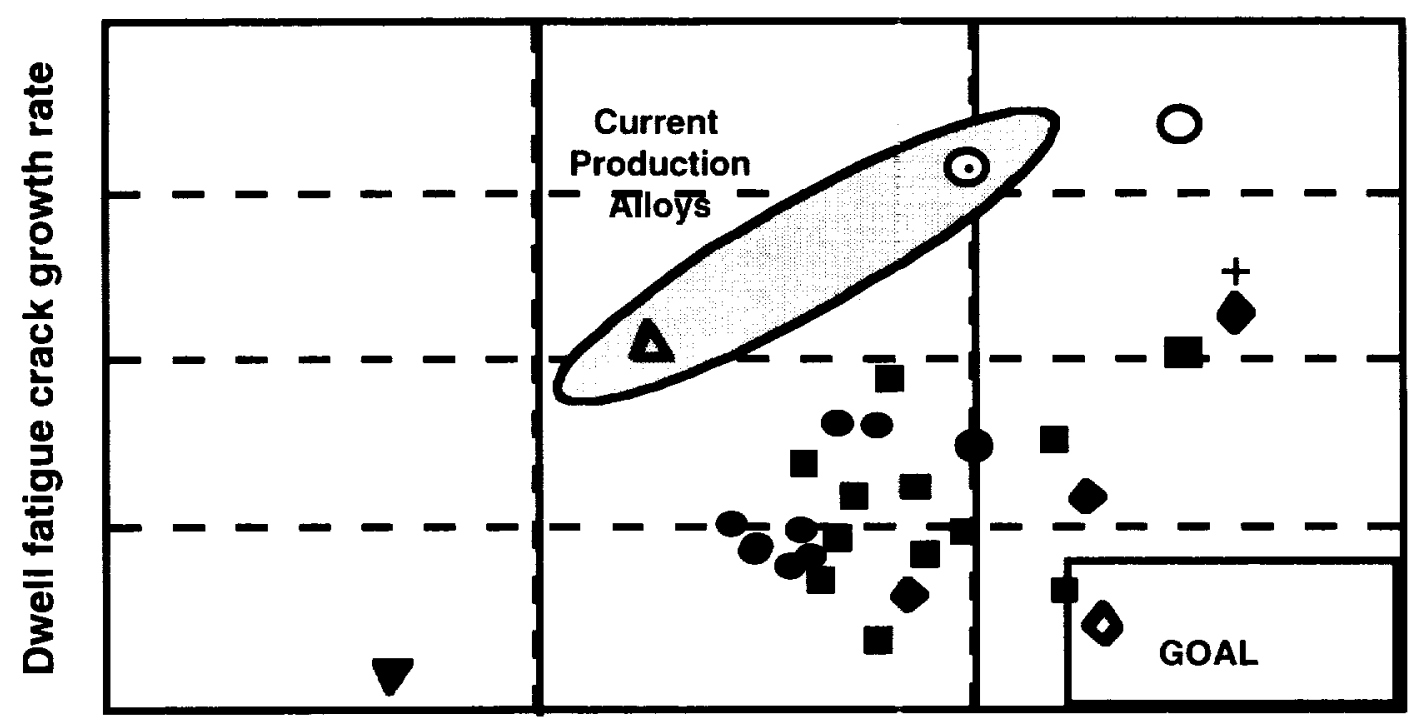

Hours to 0.2 percent creep

Figure 19.-Status of development of advanced turbomachinery disk alloy.

HSCT airfoil alloy developed

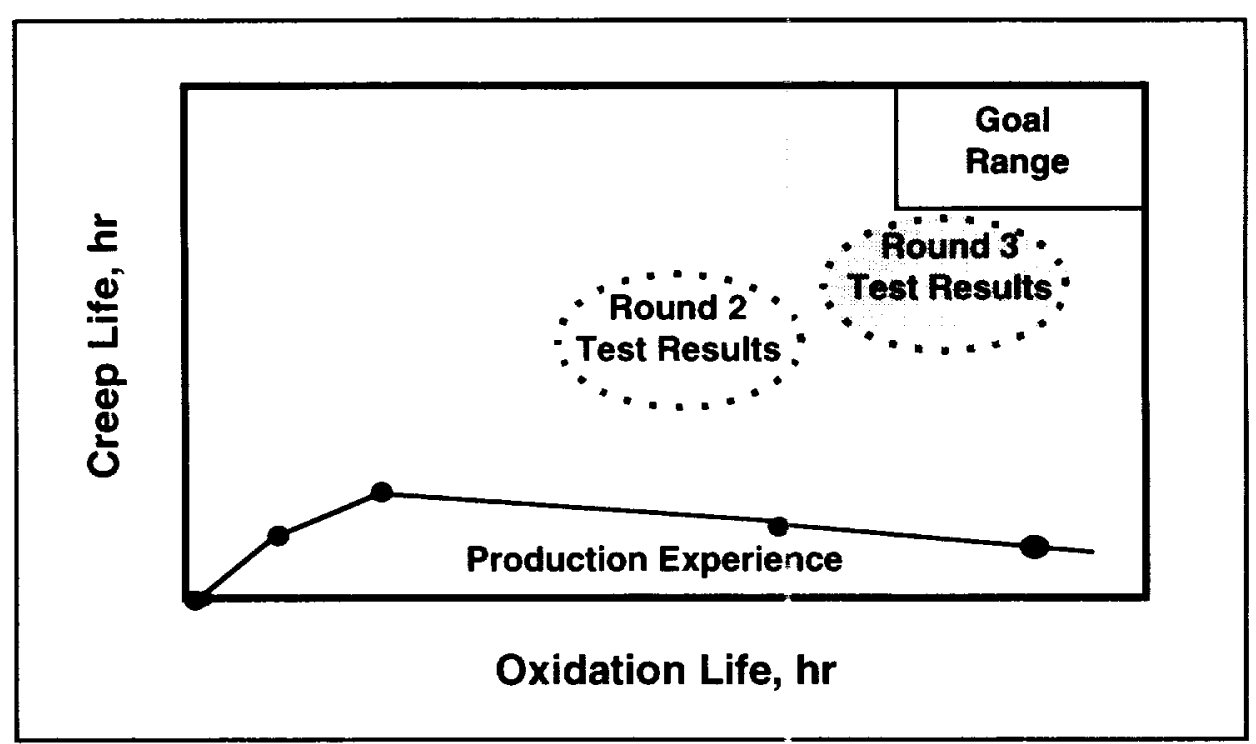

Figure 20.-Status of development of advanced turbine airfoil alloy. 


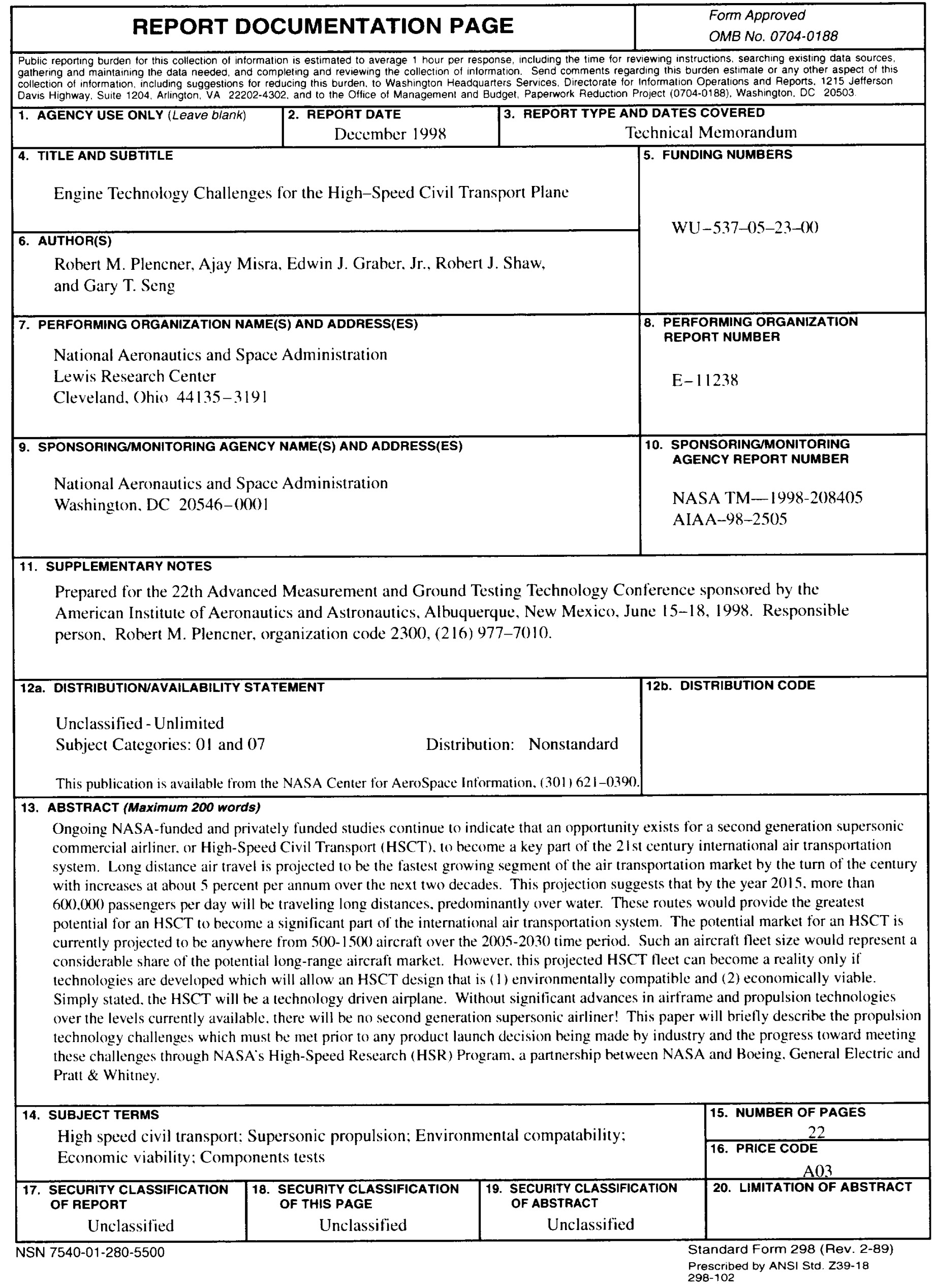


